\title{
GMR
}

\section{Mutational screening in the LDLR gene among patients presenting familial hypercholesterolemia in the Southeast of Brazil}

\author{
G.A. Molfetta ${ }^{1,2,3}$, D.L. Zanette ${ }^{1,3}$, J.E. Santos ${ }^{4}$ and W.A. Silva Jr. ${ }^{1,2,3}$ \\ ${ }^{1}$ Departamento de Genética, Faculdade de Medicina de Ribeirão Preto, \\ Universidade de São Paulo, Ribeirão Preto, SP, Brasil \\ ${ }^{2}$ Centro de Medicina Genômica, \\ Hospital das Clínicas da Faculdade de Medicina de Ribeirão Preto, \\ Universidade de São Paulo, Ribeirão Preto, SP, Brasil \\ ${ }^{3}$ Instituto Nacional de Ciência e Tecnologia em Células-Tronco e Terapia Celular, \\ Fundação Hemocentro de Ribeirão Preto, Universidade de São Paulo, \\ Ribeirão Preto, SP, Brasil \\ ${ }^{4}$ Departamento de Clínica Médica, Faculdade de Medicina de Ribeirão Preto, \\ Universidade de São Paulo, Ribeirão Preto, SP, Brasil \\ Corresponding author: W.A. Silva Jr. \\ E-mail: wilsonjr@usp.br
}

Genet. Mol. Res. 16 (3): gmr16039226

Received February 7, 2017

Accepted August 4, 2017

Published August 31, 2017

DOI http://dx.doi.org/10.4238/gmr16039226

Copyright (C) 2017 The Authors. This is an open-access article distributed under the terms of the Creative Commons Attribution ShareAlike (CC BY-SA) 4.0 License.

ABSTRACT. Familial hypercholesterolemia (FH) is a dominant,
autosomal disease characterized by high LDL levels in blood plasma,
and is caused by a defect in the gene encoding the LDL receptor
(LDLR). The clinical diagnosis is based on personal and familial history,
physical examination findings, and measures of high LDL cholesterol
concentrations. LDLR is a cell-surface glycoprotein that controls the
level of blood plasma cholesterol and triglyceride by LDLR-mediated
endocytosis. Here we sequenced the entire LDLR gene-coding region
to screen for mutations in 32 patients diagnosed with FH, and we have
found 20 mutations including synonymous, missense, and intronic

Genetics and Molecular Research 16 (3): gmr16039226 
mutations. Six of them were characterized as pathogenic mutations (D178Y, C184Y, S326C, C681X, IVS7+10G >C, and IVS11-10G>A). We have also found one intronic mutation not described so far (IVS11$63 \mathrm{C}>\mathrm{A}$ ). Our study corroborates the broad spectrum of mutations distributed along the entire LDLR gene, and we suggest that the genes APOB and PCSK9 should also be screened for mutations when considering the diagnosis of FH. It is already known that different types of mutations are directly associated with the phenotype heterogeneity presented by patients. Considering that Brazilian population is highly admixed, it is important to determine the geographic spectrum of LDLR mutations to provide information on the prognosis and treatment of each FH patient.

Key words: Familial hypercholesterolemia; LDLR gene; DNA sequencing

\section{INTRODUCTION}

Familial hypercholesterolemia (FH) is an autosomal dominant disorder characterized by i) elevations in the levels of plasma low-density lipoprotein (LDL) cholesterol; ii) tendon xanthomas, and iii) premature coronary heart disease (Hobbs et al., 1990). The LDR receptor (LDLR) is a cell-surface transmembrane protein that facilitates the uptake of plasma LDL primarily into hepatocytes, where it is further catabolized (Diakou et al., 2011). A genetic defect caused by mutations in the LDLR gene results in malfunctioning or insufficient numbers of LDLR molecules, which account for the reduced clearance of LDL molecules from the plasma via the receptor-mediated pathway (Diakou et al., 2011).

However, mutations in three other genes regulating sterol and lipoprotein pathways may lead to similar phenotypes: Apo B-100, PCSK9, and ARH (Raal and Santos, 2012). Although mutations in these other genes lead to an increase in cholesterol levels, changes in the LDLR gene has shown to be the main cause of FH (Goldstein and Brown, 2001).

$\mathrm{FH}$ is a common inherited disease with heterozygotic and homozygotic frequencies of $1 / 500$ and $1 / 10^{6}$, respectively (Varret et al., 1998). The early identification and treatment of FH probands and their affected relatives with effective lipid-lowering drugs are important as they reduce the risk of future coronary artery disease. Therefore, the molecular characterization of the LDLR gene appears to be a useful tool for the correct diagnosis of FH since it provides an unequivocal result.

The study of the molecular defects of the LDLR in Brazil was initiated by Figueiredo et al. (1992) and Alberto et al. (1999). These researchers identified the molecular basis of FH in 16 families. They found a family in which the defect was a deletion of $4 \mathrm{~kb}$ involving exons 13 and 14 of the LDLR gene. Also, they observed that 14 families were carriers of Lebanese allele, a nonsense mutation in exon 14 that results in the production of a truncated protein without functional activity. The Lebanese allele is the most common molecular defect identified in patients with FH in Brazil. Due to the great diversity of Brazilian population, the spectrum of mutations in the LDLR gene may be broad, and the molecular basis of the FH in Brazil has not been characterized so far. According to data from the World Health Organization (1999), it is estimated that about 320,000 individuals are heterozygous for FH in

Genetics and Molecular Research 16 (3): gmr16039226 
Brazil. The aim of this study was to carry out the molecular characterization of patients with a clinical diagnosis of FH in Brazil and to describe the mutation heterogeneity.

\section{PATIENTS AND METHODS}

A total of 32 patients with a clinical diagnosis of FH from the Nutrition Unit of the Medical School of Ribeirão Preto, University of São Paulo, participated in the study and had signed for the consented blood taken at our Institution's Ethics Committee.

\section{DNA extraction and PCR}

Genomic DNA was extracted from peripheral blood lymphocytes through the Wizard Genomic DNA Purification kit (Promega), according to the manufacturer's instructions. The entire LDLR gene-coding region was amplified with the specific sense and anti-sense primers that flanked each intron/exon (Table S1). All PCRs were standardized with the following reactants for each reaction: $2.5 \mathrm{mM}$ of each primer, $2.5 \mathrm{mM}$ dNTPs, $2.5 \mu \mathrm{L} 1 \mathrm{X}$ buffer (Biotools), $1 \mathrm{U}$ Taq polymerase (Biotools); $200 \mathrm{ng}$ genomic DNA, and $14 \mu \mathrm{L}$ distilled water for a $25-\mu \mathrm{L}$ final volume.

\section{DNA sequencing}

DNA fragments amplified by PCR were subjected to direct sequencing in an automatic capillary sequencing system ABI Prism 377 DNA Sequencer ${ }^{\circledR}$ (Life Technologies), using the ABI Prism Big Dye ${ }^{\mathrm{TM}}$ Terminator Cycle Sequencing Ready Reaction ${ }^{\circledR}$ kit, following the manufacturer's instructions. The sequencing results were analyzed through FinchTV version 1.4.0 (Geospiza Inc., 2004-2006) and Polyphred (Geospiza Inc.) programs; the sequences obtained were compared to the reference from the GenBank (NM_000527).

\section{RESULTS AND DISCUSSION}

A total of 20 mutations (Tables 1 and 2) were identified among the 32 patients with clinical diagnosis of $\mathrm{FH}$ enrolled in this study. Of the 20 mutations, eight of them were found within the exon region (Table 1) and 12 were found within the intron region (Table 2). The most frequent mutation causing $\mathrm{FH}$ among our cohort was the putative splicing mutation IVS7+10G $>$ C (42\%), followed by the mutations C681X (9\%), D178Y (4\%), and S326C (2\%) (Table 3).

\section{Table 1. Mutations localized in the coding region of the LDLR gene.}

\begin{tabular}{l|c|c|c|l}
\hline Exons & Nucleotide change & Amino acid change & dbSNP ID & References \\
\hline 4 & c. $625 \mathrm{G}>\mathrm{T}$ & D178Y & - & Humphries et al., 2006 \\
\hline 4 & c. $644 \mathrm{G}>\mathrm{A}$ & C184Y & rs121908039 & Lee et al., 1998 \\
\hline 7 & c. $1070 \mathrm{C}>\mathrm{G}$ & S326C & - & van de Kerkhof et al., 2003 \\
\hline 12 & c. $1818 \mathrm{C}>\mathrm{T}$ & L575L & rs1799898 & Boright et al., 1998 \\
\hline 12 & c. $1866 \mathrm{~T}>\mathrm{C}$ & N591N & rs688 & Boright et al., 1998 \\
\hline 13 & c. $2052 \mathrm{C}>\mathrm{T}$ & V653V & rs5925 & Leitersdorf et al., 1989 \\
\hline 14 & c. $2136 \mathrm{C}>\mathrm{A}$ & C681X & rs121908031 & Lehrman et al., 1987 \\
\hline
\end{tabular}

Genetics and Molecular Research 16 (3): gmr16039226 


\begin{tabular}{|c|c|c|c|}
\hline Introns & Mutation & dbSNP ID & References \\
\hline 6 & IVS6+36G $>$ A & $\mathrm{rs} 13306513$ & - \\
\hline 11 & IVS11-63C $>$ A & - & Described in this study \\
\hline 12 & IVS12-119C $>\mathrm{T}$ & rs2569549 & - \\
\hline 12 & IVS12-48C $>\mathrm{T}$ & rs187762599 & - \\
\hline 16 & IVS16+48G $>A$ & rs13306501 & - \\
\hline 7 & IVS7+10G $>C$ & rs 12710260 & Dedoussis et al., 2004 \\
\hline 11 & IVS11-10G $>A$ & rs1724882 & Cenarro et al., 1998 \\
\hline 16 & IVS16+47C $>$ T & rs 2738460 & Amsellem et al., 2002 \\
\hline 16 & IVS16+116G $>A$ & rs 2304182 & Amsellem et al., 2002 \\
\hline 17 & IVS17-53G $>A$ & rs6413503 & Amsellem et al., 2002 \\
\hline 17 & IVS17-42G $>A$ & rs6413504 & Amsellem et al., 2002 \\
\hline 18 & $* 52 \mathrm{G}>\mathrm{A}$ & rs14158 & Amsellem et al., 2002 \\
\hline
\end{tabular}

Table 3. LDLR pathogenic mutations in Brazilian patients with FH.

\begin{tabular}{|c|c|c|c|c|c|}
\hline \multirow[t]{2}{*}{ Region } & \multicolumn{3}{|c|}{ Mutations* } & \multirow[t]{2}{*}{ Allele frequency } & \multirow[t]{2}{*}{ Patient frequency } \\
\hline & Nucleotide position & Amino acid position & Type** & & \\
\hline \multicolumn{6}{|l|}{ Exon } \\
\hline 4 & c. $625 \mathrm{G}>\mathrm{T}$ & D178Y & Missense & $4 \%$ & $8 \%$ \\
\hline 4 & c. $644 \mathrm{G}>\mathrm{A}$ & $\mathrm{C} 184 \mathrm{Y}$ & Missense & $2 \%$ & $3 \%$ \\
\hline 7 & c. $1070 \mathrm{C}>\mathrm{G}$ & S326C & Missense & $2 \%$ & $3 \%$ \\
\hline 14 & c. $2136 \mathrm{C}>\mathrm{A}$ & C681X & Nonsense & $9 \%$ & $21 \%$ \\
\hline \multicolumn{6}{|l|}{ Intron } \\
\hline 7 & IVS7 $+10 \mathrm{G}>\mathrm{C}$ & - & Splicing & $42 \%$ & $59 \%$ \\
\hline 11 & IVS11-10G $>A$ & - & Splicing & $2 \%$ & $3 \%$ \\
\hline
\end{tabular}

The articles of Figueiredo et al. (1992) and Alberto et al. (1999) are considered the first studies that reported the molecular characterization of FH caused by a deficiency of the LDLR gene in Brazil. These studies reported two mutations as the cause of FH in their patients: a 4-kb deletion involving exons 13 and 14 of the LDLR gene and the mutation C681X that creates a stop codon and the production of a truncated protein or a protein partially translated. We have detected the same C681X mutation in $21 \%$ of our patients. Lehrman et al. (1987) described the mutation C681X as producing a shortened receptor protein lacking three domains: the region of clustered 0 -linked carbohydrates, the membrane-spanning region, and the cytoplasmic tail. The truncated protein retains only two domains: a whole ligand-binding region and a partial epidermal growth factor precursor homology region. The high frequency of this mutation among Lebanese and Syrian subjects may be attributed to a founder effect, and this mutation is also known as the Lebanese allele because of the high incidence among those populations (Lehrman et al., 1987).

The third higher frequency mutation was the D178Y causing FH in $8 \%$ of the patients. This mutation was reported by Humphries et al. (2006) as pathogenic, causing the FH with high concentrations of serum cholesterol, LDLC, HDLC, and triglyceride in addition to the typical clinical features of xanthoma, corneal arcus, and xanthelasma.

The mutation S326C was found in 3\% of patients here evaluated and was already described as the cause of FH by van de Kerkhof et al. (2003). This mutation was detected for the first time in a Brazilian patient presenting two mutations: C681X and the mutation S326C, confirming the diagnosis of homozygous FH.

We identified mutations spread along the entire LDLR gene emphasizing the higher presence of mutations in intron 7 and exons 4 and 14. These results agree with some data reported in the literature where exons $4,10,13$, and 14 were described to bear the majority of the mutations in the LDLR gene (Schmidt and Kostner, 2000; Humphries et al., 2006).

Genetics and Molecular Research 16 (3): gmr16039226 
Regarding the mutations localized close to the splicing sites, mutations IVS7+10G $>\mathrm{C}$ and IVS11-10G $>\mathrm{A}$ are characterized by altering the mRNA processing donor and acceptor sites, respectively (Cenarro et al., 1998; Dedoussis et al., 2004). Mutation IVS7+10G $>$ C was the most frequent cause of $\mathrm{FH}$ in our patients (59\%) while mutation IVS11-10G $>$ A presented the lowest frequency among our patients $(3 \%)$.

Dedoussis et al. (2004) described the potential new splice site mutation IVS7+10G $>$ C (c.1060+10G $>$ C). Regarding the pathogenic effect of this splicing mutation, Amsellem et al. (2002) described the same position intron mutation c.1060+10G $>A$, which could disrupt splicing by its computer estimated potential to create aberrant donor splicing site in close vicinity to original site. These authors say that the IVS $7+10$ variant could be a minor variant partially reducing LDLR expression by the competition of the aberrant donor splice with the original donor site. Accordingly, heterozygous carriers of this variant expressed a mild phenotype of FH.

Despite these observations, to the best of our knowledge, the actual effect of these mutations on LDLR splicing was not confirmed so far. Here we speculate whether the same causing disease splicing mechanism could be observed by the mutation IVS7+10G $>C$ as they are localized at the same position.

Regarding other synonymous mutations that we have found, Dementieva et al. (2012) have already reported that L575L and R744R in the LDLR gene did not show a significant relationship with coronary artery disease.

Furthermore, one intron mutation is reported for the first time in this study. Table 3 shows more details about the SNPs that were found among our sample of patients presenting FH. Figure 1 demonstrates all the 20 LDLR gene mutations detected in this study.

\section{Exon Mutation}

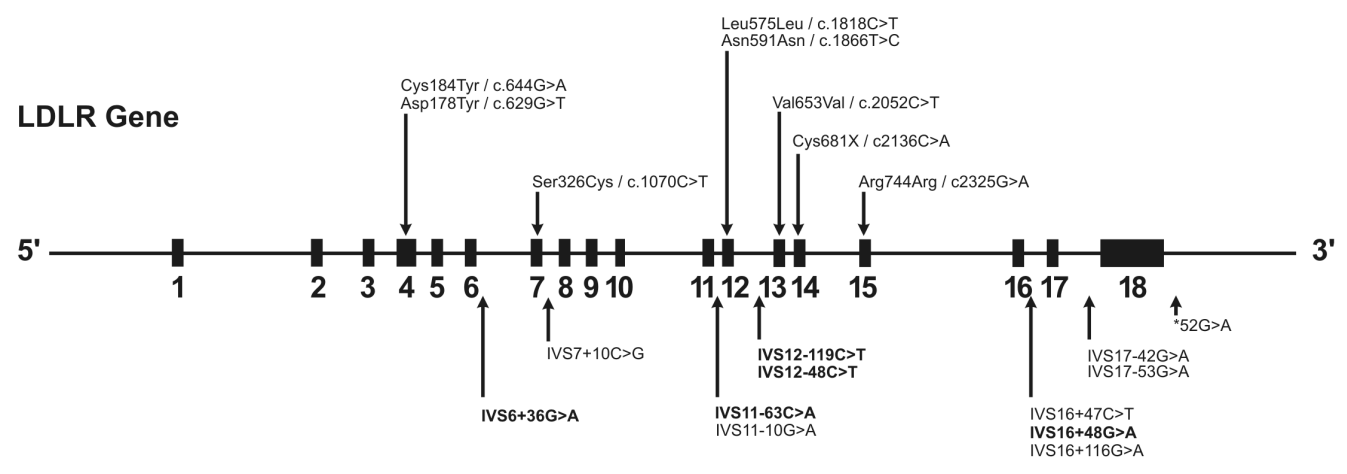

Intron Mutation

Figure 1. Schema showing the position of each mutation identified in this study. In regular font are the mutations already described in the literature and in black are the mutations described for the first time in our study.

Salazar et al. (2000) also defined the molecular basis of a group of FH patients living in the city of São Paulo. All of their patients are of European origin. They identified 15 mutations in the LDLR gene located in different exons. Of the 15 mutations, seven were described for the first time in a Brazilian population; five of them were missense mutations, and two of

Genetics and Molecular Research 16 (3): gmr16039226 
them were frameshift mutations. Interestingly, none of the mutations described by Salazar et al. (2000) was identified among our patients. We can point out one reason for this result: we suggest that the most likely situation is that the groups are of different ethnical origin. We do not have the race self-information of our patients; on the other hand, we know that our cohort of patients is quite heterogenic as they come from various cities in the Northeast region of the state. Corroborating these findings, Komarova et al. (2013) have already demonstrated that each megapolis has its own FH mutation spectrum sharing only small part of mutations with other populations.

Based on our data and on the previous data from Figueiredo et al. (1992) and Alberto et al. (1999), we are encouraged to affirm that mutations IVS7+10G $>C$ and C681X may be a cause of FH in the Southeast Brazil and should be at first investigated when considering the clinical hypothesis of $\mathrm{FH}$ in this region. Furthermore, if considering an expanded panel of mutations, six mutations (Table 3) should be screened for the FH diagnosis among patients in this same region.

If common LDLR mutations are known in a population, selected panels of mutations can be used as the first strategy. On the other hand, in a population where no founder effect was detected or in a population where we find a great genetic heterogeneity, the gold-standard approach remains on the full sequencing of the LDLR-coding region followed by the search of APOB and PCSK9 gene defects (Izar et al., 2010). A recent study using the next-generation sequencing (NGS) to screen for a mutation in the three genes LDLR, APOB, and PCSK9 say that the NGS methodology could provide one rapid route to increasing the present low percentage of FH cases with a genetic diagnosis (Norsworthy et al., 2014). Regarding the seven patients who showed no mutations, the presence of the FH may probably be associated with other genes as APOB and PCSK9, as mutations in these two other genes cause patients presenting a similar phenotype to the ones with mutations in LDLR (Austin et al., 2004; Slimani et al., 2012).

At least but not last, there is an influence of the presence and type of the LDLR mutation on the lipid profile and the response to lipid-lowering therapy (Santos et al., 2014). These observations are of fundamental importance to characterize the molecular basis of FH in Brazil and its treatment as it reveals that FH may be associated with different genes besides the LDLR gene, and targeted pharmacological treatment should be performed in patients carrying an LDLR mutation.

We can summarize that of the mutations already described as associated with $\mathrm{FH}$, six were identified in our study: IVS7+10C $>$ G, C681X, D178Y, S326C, C184Y, and IVS11$10 \mathrm{G}>\mathrm{A}$. Four of them are situated in the coding region, exon 4 (D178Y and C184Y), exon 7 (S326C), and exon 14 (C681X). The two remaining mutations are located in introns 7 (IVS7+10C $>\mathrm{G}$ ) and 11 (IVS11-10G $>A$ ), and are associated with FH because they alter the processing of DNA. The most frequent among our patients was the IVS7 $+10 \mathrm{C}>\mathrm{G}$, representing $59 \%$ of patients followed by the mutation C681X representing $21 \%$ of the patients. We also describe that the genes APOB and PCSK9 should be screened together with the LDLR gene. The NGS is a good approach for the molecular diagnosis of FH as this disease is caused by a distinct set of genes involved in the phenotype and showing a high prevalence in the community.

The present study contributes to a better knowledge of the genetic basis of $\mathrm{FH}$ in Brazil. It is already known that different types of mutations are directly associated with the phenotype heterogeneity presented by patients. Considering that the Brazilian population is

Genetics and Molecular Research 16 (3): gmr16039226 
highly admixed, it is important to determine the geographic spectrum of LDLR mutations to provide information on the prognosis and treatment of each patient with high cholesterol levels or under lowering cholesterol therapy.

\section{Conflicts of interest}

The authors declare no conflict of interest.

\section{REFERENCES}

Alberto FL, Figueiredo MS, Zago MA, Araújo AG, et al. (1999). The Lebanese mutation as an important cause of familial hypercholesterolemia in Brazil. Braz. J. Med. Biol. Res. 32: 739-745. https://doi.org/10.1590/S0100$\underline{879 X 1999000600009}$

Amsellem S, Briffaut D, Carrié A, Rabès JP, et al. (2002). Intronic mutations outside of Alu-repeat-rich domains of the LDL receptor gene are a cause of familial hypercholesterolemia. Hum. Genet. 111: 501-510. https://doi.org/10.1007/ s00439-002-0813-4

Austin MA, Hutter CM, Zimmern RL and Humphries SE (2004). Familial hypercholesterolemia and coronary heart disease: a HuGE association review. Am. J. Epidemiol. 160: 421-429. https://doi.org/10.1093/aje/kwh237

Boright AP, Connelly PW, Brunt JH, Morgan K, et al. (1998). Association and linkage of LDLR gene variation with variation in plasma low density lipoprotein cholesterol. J. Hum. Genet. 43: 153-159. https://doi.org/10.1007/ $\underline{\mathrm{s} 100380050060}$

Cenarro A, Jensen HK, Casao E, Civeira F, et al. (1998). Identification of recurrent and novel mutations in the LDL receptor gene in Spanish patients with familial hypercolesterolemia. Hum. Mutat. 11: 413. https://doi.org/10.1002/ (SICI) 1098-1004(1998)11:5<413::AID-HUMU17>3.0.CO;2-F

Dedoussis GV, Genschel J, Bochow B, Pitsavos C, et al. (2004). Molecular characterization of familial hypercholesterolemia in German and Greek patients. Hum. Mutat. 23: 285-286. https://doi.org/10.1002/humu.9218

Dementieva Y, Green TL, Primerano DA, Wei L, et al. (2012). Identification of genes contributing to cardiovascular disease in overweight and obese individuals from West Virginia. The Free Library of January 1, 2012, [http://www. thefreelibrary.com/Identification of genes contributing to cardiovascular disease in...-a0276187085].

Diakou M, Miltiadous G, Xenophontos SL, Manoli P, et al. (2011). Spectrum of LDLR gene mutations, including a novel mutation causing familial hypercholesterolaemia, in North-western Greece. Eur. J. Intern. Med. 22: e55-e59. https:// doi.org/10.1016/j.ejim.2011.01.003

Figueiredo MS, Dos Santos JE, Alberto FL and Zago MA (1992). High frequency of the Lebanese allele of the LDLr gene among Brazilian patients with familial hypercholesterolaemia. J. Med. Genet. 29: 813-815. https://doi.org/10.1136/ img.29.11.813

Goldstein JL and Brown MS (2001). Molecular medicine. The cholesterol quartet. Science 292: 1310-1312. https://oi. org $/ 10.1126 /$ science. 1061815

Hobbs HH, Russell DW, Brown MS and Goldstein JL (1990). The LDL receptor locus in familial hypercholesterolemia: mutational analysis of a membrane protein. Annu. Rev. Genet. 24: 133-170. https://doi.org/10.1146/annurev. ge.24.120190.001025

Humphries SE, Cranston T, Allen M, Middleton-Price H, et al. (2006). Mutational analysis in UK patients with a clinical diagnosis of familial hypercholesterolaemia: relationship with plasma lipid traits, heart disease risk and utility in relative tracing. J. Mol. Med. (Berl.) 84: 203-214. https://doi.org/10.1007/s00109-005-0019-z

Izar MC, Machado VA and Fonseca FA (2010). Genetic screening for homozygous and heterozygous familial hypercholesterolemia. Appl. Clin. Genet. 3: 147-157.

Komarova TY, Korneva VA, Kuznetsova TY, Golovina AS, et al. (2013). Familial hypercholesterolemia mutations in Petrozavodsk: no similarity to St. Petersburg mutation spectrum. BMC Med. Genet. 14: 128-132. https://doi. org/10.1186/1471-2350-14-128

Lee WK, Haddad L, Macleod MJ, Dorrance AM, et al. (1998). Identification of a common low density lipoprotein receptor mutation (C163Y) in the west of Scotland. J. Med. Genet. 35: 573-578. https://doi.org/10.1136/jmg.35.7.573

Lehrman MA, Schneider WJ, Brown MS, Davis CG, et al. (1987). The Lebanese allele at the low density lipoprotein receptor locus. Nonsense mutation produces truncated receptor that is retained in endoplasmic reticulum. J. Biol. Chem. 262: 401-410.

Genetics and Molecular Research 16 (3): gmr16039226 
Leitersdorf E, Van der Westhuyzen DR, Coetzee GA and Hobbs HH (1989). Two common low density lipoprotein receptor gene mutations cause familial hypercholesterolemia in Afrikaners. J. Clin. Invest. 84: 954-961. https://doi. org/10.1172/JCI114258

Norsworthy PJ, Vandrovcova J, Thomas ER, Campbell A, et al. (2014). Targeted genetic testing for familial hypercholesterolaemia using next generation sequencing: a population-based study. BMC Med. Genet. 15: 70. https:// doi.org/10.1186/1471-2350-15-70

Raal FJ and Santos RD (2012). Homozygous familial hypercholesterolemia: current perspectives on diagnosis and treatment. Atherosclerosis 223: 262-268. https://doi.org/10.1016/j.atherosclerosis.2012.02.019

Salazar LA, Cavalli SA, Hirata MH, Diament J, et al. (2000). Polymorphisms of the low-density lipoprotein receptor gene in Brazilian individuals with heterozygous familial hypercholesterolemia. Braz. J. Med. Biol. Res. 33: 1301-1304. https://doi.org/10.1590/S0100-879X2000001100006

Santos PC, Morgan AC, Jannes CE, Turolla L, et al. (2014). Presence and type of low density lipoprotein receptor (LDLR) mutation influences the lipid profile and response to lipid-lowering therapy in Brazilian patients with heterozygous familial hypercholesterolemia. Atherosclerosis 233: 206-210. https://doi.org/10.1016/j.atherosclerosis.2013.12.028

Schmidt H and Kostner GM (2000). Familial hypercholesterolemia in Austria reflects the multi-ethnic origin of our country. Atherosclerosis 148: 431-432. https://doi.org/10.1016/S0021-9150(99)00469-4

Slimani A, Jelassi A, Jguirim I, Najah M, et al. (2012). Effect of mutations in LDLR and PCSK9 genes on phenotypic variability in Tunisian familial hypercholesterolemia patients. Atherosclerosis $222: 158-166$. https://doi.org/10.1016/j. atherosclerosis.2012.02.018

van de Kerkhof L, Van Eijk SJ, Defesche JC and Dos-Santos JE (2003). Identification of a new mutation, S305C, in exon 7 of the low-density lipoprotein receptor gene in a Brazilian family with homozygous familial hypercholesterolemia. Genet. Test. 7: 77-79. https://doi.org/10.1089/109065703321560994

Varret M, Rabés JP, Thiart R, Kotze MJ, et al. (1998). LDLR Database (second edition): new additions to the database and the software, and results of the first molecular analysis. Nucleic Acids Res. 26: 248-252.

World Health Organization (1999). Familial Hypercholesterolemia: report of a second WHO consultation. (WHO/HGN/ $\mathrm{FH} / \mathrm{CON} / 99.2$ ).

\section{Supplementary material}

Table S1. List of primers used for sequencing the promoter and coding regions of the LDLR gene.

Genetics and Molecular Research 16 (3): gmr16039226 